\title{
Review on Canine Transmissible Venereal Tumor (CTVT)
}

\author{
Yimesgen Tarekegn Abeka* \\ Jimma university, college of agriculture and veterinary medicine, Ethiopia
}

Submission: : June 02, 2019; Published: July 30, 2019

"Correspondence Author: Yimesgen Tarekegn Abeka, Jimma university, college of agriculture and veterinary medicine, Ethiopia

Abstract

Tumor is an excessive and uncoordinated proliferation of cells with no useful function. It is a common cause of death in dog. Canine transmissible venereal tumor (CTVT) is a tumor of the dogs and other canines that mainly affect the external genitalia and is transmitted from animal to animal through sexual contacts but may also be passed on as the dog bites, sniffs or licks the tumor affected areas. It is the only known naturally occurring tumor that can be transplanted as an allograft across major histocompatibility (MHC) barriers within the same species, and even to other members of the canine family, such as foxes, coyotes and wolves. The tumor is usually seen in young, sexually active dogs from an environment with high concentration of free-roaming dogs with uncontrolled reproduction. The progression of this tumor is unique in that, it follows a predictable growth pattern. Clinical signs of this disease include friable nodule in the genitalia, accompanied by hemorrhagic discharge. Definitive diagnosis is reached by cytological and histopathological findings. It is many times, self-limiting. As a form of treatment chemotherapy, surgery, radiotherapy and immunotherapy may be used. Cancer chemotherapy is the best option.

Keywords: Canine Transmissible Venereal Tumor; Diagnosis; Dog; Major Histocompatibility Complex; Treatment

\section{Introduction}

Tumor is a genetic disease. Damage to the cellular genome is a common feature for virtually all neoplasms, despite the facts that neoplasms arise in a broad variety of tissues and that diverse agents such as viruses, mutagenic chemicals, and radiation induce their outgrowth. The genetic damage produced by carcinogens is believed to be random, and many mutations may be inconsequential [1]. Canine transmissible venereal tumor (CTVT) also known as Sticker's sarcoma, Sticker tumor, transmissible venereal tumor (TVT), contagious venereal tumor, transmissible lymphosarcoma, transmissible venereal sarcoma, veneral granuloma, infectious granuloma, canine condyloma, infectious sarcoma and contagious lymphosarcoma [2].

Transmissible venereal tumor (TVT) is a horizontally transmitted venereal round cell tumor diagnosed in dogs [3]. It is naturally occurring tumor transmitted from animal to animal during copulation by viable tumor cells that mainly affect the external genitalia and occasionally the internal genita-lia, although in some cases it can be found in extra genital sites as well [4]. The transmissible agent causing this disease is thought to be the tumor cell itself [5]. It is a contagious cancer that is transmitted along with viable cells and fails to cross the barriers of the major histocompatibility complex (MHC) between dogs and between family members in the Canidae family such as foxes, coyotes, wolves and jackals [6].

These tumors remain a big problem in countries where mating of dogs is not under control, and it is readily transmitted from one dog to the other through injured skin and mucosa [4]. This disease is mostly observed in free-roaming, sexually active dogs in tropical and subtropical regions such as the southern US, Central and South America, southeast Europe, Ireland, Japan, and China [7]. One of the consequences of tumoral malignancy is a gradual loss of the patient's weight, a condition that may deteriorate to the state of cachexia [8]. Dogs with this disease experience pain, haemorrhages and exhibit serosanguineous discharge in the external genitalia. Usually cauliflower like in appearance, friable, and red to flesh colored [9].

The tumor does not often metastasize except in puppies and immunocompromized dogs. Some invasive agents which reduce immune response of the host could cause persistence of the lesions [10]. Tentative diagnosis is based on history of animal, and clinical findings. Definitive diagnosis is based on cytological and histological findings [11]. Treatments including surgery, 
radiotherapy, and chemotherapy have been used to treat this disea-se [9]. Therefore, the objectives of this seminar paper are: To review the currently available articles of TVT in dog and its therapeutic options.

\section{History of TVT}

Transmissible tumors in the animal world are rare, and thus have always attracted scientific attention. As a clinical entity in veterinary medicine, Canine TVT was initially described in Europe by Russian veterinarian Novinsky in 1876, when he demonstrated that the tumor could be transplanted from one dog to another by infecting them with tumor cells [12]. The genetic ancestor was recently investigated by Rebbeck, who determined that the neoplasia probably arose from a dog or wolf rather than from a distant member of the canidae family [13]. The tumor is of clonal origin, with asexual reproduction and a near-constant karyotypic variation of 58-59 chromosomes, which sets it apart from the normal chromosomes number of 78 in dogs. Both these biological facts have led some authors to look at TVT as an example of the successful evolution of a cancer cell into a dog specific unicellular parasite and to a "new parasitic dog species" of worldwide distribution [14].

It is considered a tumor which first developed in dogs or wolfs around 200 to 2500 years ago and since then it has been transmitted as an allograft. The cells behave as infectious cancer cells, capable of growing autonomously from the host [15]. More recently, a single clone became dominant and then divided into two groups with a worldwide distribution. This evidence indicates that this disease is the oldest transplantable somatic cell clone known [16].

\section{Etiology}

There was no single element or condition that causes cancer. Rather, cancer usually occurs as a result of numerous factors that interact over an extended period of time. The observation that cancer occurs with a higher frequency in older patients supports the concept that passage of time allows for the series of events required for a normal cell to transform into a cancer cell [1]. Infectious viral agents have been implicated as causal factors for a variety of transmissible tumor types in humans and animals, but in TVT, the infectious agent is the cancer cell itself and the tumor is clonal in origin. Cells can be derived following mutations induced by viruses, chemicals or radiation of lymphohistiocytic cells and that these clones of tumor cells can then be dissemina-ted by allogeneic transplantation. All tumor cells of this type of cancer share extremely similar genetic code, often if not always unrelated to the DNA of their host. Specifically, the long interspersed nuclear element (LINE1 ) in the tumor cells is in a different location than in normal canine DNA [5]. This demonstrates that the tumor do not arise from separate cancerous transformation in individual animals. Rather, the malignant tumor cells from one dog are transferred to another [15].

\section{Epidemiology}

Understanding the epidemiology of CTVT will provide insights population that may experience it's exposure and information about disease prevalence [17].

\section{Distribution}

TVT has been recorded in all continents during the 20th century; Asia, America, Africa and Australia, yet this does not mean that it was previously absent from those regions. The disease is globally widespread, particularly in sub-tropical countries, with cases reported in North, Central and South America, Europe, Middle and Far East, Asia and parts of Africa [18]. Naturally occurring TVT cases have been reported in 33 different countries worldwide. It is considered to be endemic in many tropical and subtropical countries with free-roaming/ stray dog breeding populations, which allows for a continued local propagation because of the uncontrolled population of stray dogs and the inadequacy of exerting effective treatments. Sexually mature dogs (more than two years old) most commonly affected [4].

\section{Factors affecting the prevalence and incidence of TVT}

Prevalence of the acquired diseased condition differed with geographical area (urban and rural area). It has been recorded all over the world and in India incidence of this disease in dogs is reported to range from $23-43 \%$. It is most common in subtropical to tropical urban areas. The incidence of this disease is more restricted to the age of greatest sexual activity and in countries where canine population is not subject to a strict epidemiological control. Females are infected more often than males [19].

\section{Season}

Variation in season has been implicated and correlated with estrus cycle in canines. The canines exhibit the estrus in rainy and summer season. When the infection is transmitted in rainy season the granulomatous growth is discernible after 2-3 months in winter season. The incidence of venereal granuloma in winter season is comparatively more. Canines also exhibit estrus in the months of February and March and the infection is transmitted and the growth is reported in rainy season after 2-3 months. Therefore, the incidences of venereal granuloma in rainy season ranked 2nd [4].

\section{Sex}

More incidences in females are occurring as compared to males. Male dogs, which are constantly sexually receptive, may have greater opportunity to spread the disease, in contrast to females, which become sexually receptive only once every 6-7 months. Indeed, observed that a single TVT affected male dog spread the disease to 11 of 12 females, and at least in some regions is naturally found with greater prevalence in females than in males. Therefore, the incidence of venereal gra-nuloma 


\section{Cancer Therapy \& Oncology International Journal}

was found more in females as compared to males (Table 1) [12] Table 1: Age, and sex frequency incidence of TVT in dogs.

\begin{tabular}{|c|c|c|c|}
\hline Age(years) & Male & Female & total \\
\hline$<1$ & 0 & 0 & 0 \\
\hline 1 & 3 & 2 & 5 \\
\hline 2 & 5 & 4 & 9 \\
\hline 3 & 5 & 6 & 11 \\
\hline 4 & 0 & 5 & 5 \\
\hline 5 & 0 & 5 & 5 \\
\hline 6 & 0 & 2 & 2 \\
\hline 7 & 0 & 4 & 4 \\
\hline 8 & 1 & 4 & 5 \\
\hline$>8$ & 3 & 1 & 4 \\
\hline Total & 17 & 33 & 50 \\
\hline
\end{tabular}

\section{Age}

The CTVT was most prevalent in young to adult middle-aged dogs. The condition was found to be more at this age, which could be because the young and adult middle-aged dogs are sexually overactive and this disease being the sexually transmissible condition, such dogs are more prone for exposure. It is more common in the age group of 1-5 years. Therefore, the incidence was found more in young and adult middle-aged dogs (Table 1) [20].

\section{Mode of transmission}

TVT is a histiocytic tumor that can be transmitted among dogs and other canidies through coitus, licking, biting, and sniffing tumor affected areas [9]. It is transmitted by implantation of viable tumor cells in mucous membrane, especially if there are abrasions or loss of integrity on the surface. The concept that the tumor is naturally transmissible as an allograft came from three important observations. First, it can only be experimentally induced by transplatting living tumor cells, and not by killed cells or cell filtrates. Second, the tumor karyotins is aneuplo-id but has characteristic marker chromosomes in all tumors collected in different geographic regions. Third, a LINEinsertion near c-myc has been found in all tumors examined so far and can be used as a diagnostic marker to confirm that a tumor is CTVT [5].

It is usually transmitted to genital organs during sexual intercourse but can affect the skin via the direct implantation of tumor cells during contact between skin and tumor masses. Transplantation occurs when intact host tumor cells lose the expression of MHC class I and II molecules, enable-ng transposition of the tissue to a healthy animal by contact between skin and damaged mucosa [21]. Tumor could only be transferred between healthy animals that shared the same MHC or into immunocompromised recipients, as the tumor cells induce an immune response in healthy recipients. Cells can be derived following mutations induced by viruses, chemicals or radiation of lymphohistiocytic cells and that these clones of tumor cells can then be disseminated by allogeneic transplantation [5].

Clonal transmission is based on dogs having 78 chromosomes, 76 of which are acrocentric. Cells isolated from animals from different geographic regions, the chromosome number varies from 57 to 59 , where 15 to 17 chromosomes are metacentric or submetacentric. In addition to this unique feature, constant and specific chromosomal aberrations, such as the insertion of a LINE-1 near the c-myc oncogene in the CTVT genome, are present in most samples collected from various regions of the world. This rearrangement in the genome has not been identified in any other normal tissue of dogs and can be used for diagnosis of this disease [13].

\section{Immunology and Pathogenesis}

\section{Immunology}

TVT, morphologically belonging to the round cell type tumors (mesenchymal tissue origin), has a tumor immunohistochemical staining profile of histiocytic cells. Histiocytes are a subset of leu-kocytes that arise from bone marrow-derived stem cell precursors (mesenchymal origin), which, under the influence of cytokines, differentiate into two lineages, namely monocyte/ macrophage and dendrite. Dendrite cells, critical regulators of adaptive immune responses, are key cells in tumor antigen presentation [22].

TVT is antigenic in dogs and provokes both cell-mediated and humeral immune responses. The biological behavior of rapid growth and subsequent regression can be explained by the initial ability of the tumor cells to regulate the host's immune response by a variety of pathophysiological mechanisms. They include

(A) Lack of low-level expression of MHC-one and two on tumor cells and secretion of a B-cell cytotoxic agent(s) [23]

(B) Down regulation of monocyte-derived dendrite cell differentiation;

(C) Reduced dendrite cell survival and function [24]

(D) Limitation of the infiltration of inflammatory cells, namely T-lympho- cytes, plasma cells, and macrophages into tumor tissue, most likely through secretion of tumor derived immune-suppressive cytokines [25].

\section{Pathogenesis}

The transmission occurs by the transplantation of viable tumor cells from dog to dog, especially in regions of pronounced abrasion with loss of integrity of the mucosal surface. The progression of this tumor is unique in that, it follows a predictable growth pattern. In natural and experimental cases, the growth pattern includes progressive growth phase, static phase and regression phase, and this is followed by transplantation immunity in immunocompetent adults, while 


\section{Cancer Therapy \& Oncology International Journal}

metastasis occurs in puppies and immunosuppressed dogs [26]. The transition between the progression and regression phases of CTVT is accompanied by a significant increase in the infiltration of tumor-infiltrating lymphocytes (TILs) [5].

The initial progressive phase, which generally lasts for a few weeks, is characterized by a rapid increase in tumor volume with a doubling time of between 4 and 7 days, and an estimated loss of $50 \%$ of cells. During the progression phase the tumor cells evade immune recognition by different mechanisms. Cells from this tumor produce transforming growth factor-1 (TGF-1), and that this cytokine inhibits the activity of natural killer cells (NK) and the infiltration of cytotoxic lymphocytes and decreases MHC expression. Also secretes substances destroy B-cells and prevents the differentiation and activity of dendrite cells [27]. The proportion of B-lymphocytes in the peripheral blood decreased dramatically with CTVT growth. The destruction of B-lymphocytes was caused by substances released by the tumor cells, such as cytotoxic proteins and other circulating substances. These cytotoxic substances cause B-lympho-cyte apoptosis during the neoplastic progression phase [23]. During this phase, specific circulating antibodies to tumor antigens can be detected in affected animals. The levels of antibodies detected in the serum do not correlate well with tumor growth. This indicates that the antibodies are not protective against established this disease. Instead, the humoral response appears to have a more important role in slowing the tumor growth, protecting against metastasis, and reducing the susceptibility to future CTVT infections. After the progression phase, the tumor growth slows and becomes vulnerable to the host immune response and enter into stable phase. During the subsequent stable phase, there is markedly slower tumor growth with a doubling time of approximately 20 days, and an estimated cell loss of $8090 \%$. Following the stable phase, which can last from weeks to months to indefinitely, up to $80 \%$ of CTVT tumors enter a regressive phase during which the tumor shrinks and eventually disappears [24].

The regressive phase generally lasts between 2 and 12 weeks, during which time tumors as large as $100 \mathrm{~cm} 3$ can disappear complet. elyAlternatively, rather than entering the regressive phase, between 1 and $20 \%$ of transplanted tumors enter a second phase of rapid growth which progresse to. During the regression phase, the number of TILs increases. These cells secrete interferone- $\gamma$ (IFN- $\gamma$ ) and interleukin-6 (IL-6) which block the inhibitory effects of tumor derived TGF- $\beta$ and induce the expression of MHC in tumor cells. The expression of MHC by CTVT triggers the immune system and the regression of the tumor [24].The subsequent tumor regression period is characterized by the absence of tumor cell proliferation and increased tumor cell apoptosis, in conjunction with increased tumor infiltration by host-immune cells, and increased MHC class-one and two molecule expression on tumor cells Cell surface MHC-one and two expression allows host cells to recognize self-versus alien, and MHC-two is necessary for T-lymphocytes to recognize and initiate cytotoxic immune defense [28]. It should be noted that the presence of apoptosis, mitosis, cell proliferation, fibrosis and infiltration of TILs are good indicators of the CTVT developmental stage. Mast cells also play an important role as their numbers can be used to predict the stage of tumor evolution [29].

TVT's pathological behavior in naturally occurring disease cases versus transplantation shows subtle differences that are of clinical relevance. Although both are characterized by aggressive local growth for several months, subsequent spontaneous regression occurs rarely in naturally infected dogs and elevated erythropoietin levels, coupled with marked erythrocytosis (a clinical pathological hallmark in transplantation), have not been reported in naturally occurring infections [12]. Puppies born to previous carriers are generally also immune to subsequent tumor challenge. An immune suppression condition in the host may be required for successful secondary metastatic colonization to occur. Gross tumor appearance in mucous membranes can range from a single friable mass to multiple nodules with widespread ulceration and a tendency to bleed and/or leak tissue fluids. Attained tumor size can be large, and involvement of adjacent tissues is possible. Spread from the primary tumor site (most commonly located on the external genitals) to local adjacent lymph nodes is frequent. Metastasis (5\% to $25 \%$ in natural infections; $2 \%$ to $20 \%$ in transplantation studies) is uncommon [30]. Mast cells, which are increased in number at the tumor edges, have been implicated in the promotion angiogenesis, and thus faciletate tumor expansion [29]. Tumor dissemination is thought to occur via mechanical transplantation, local extension and hematogenous spread. Circulating neoplastic cells in the blood in an immunosuppressed dog with multiple skin nodules, suggesting hematogenous spread as a possible route for skin manifestations [31].

\section{Clinical Findings}

Clinical appearance will depend on the specific tissue/organ tumor location. Hemorrhagic discha-rge is commonly associated with mucosal, membrane based TVTs (genital, oral and/ nasal cavit-yes). The masses tend to bleed easily due to extensive ulceration of the epithelial surface lining. Genital protrusion of tumor tissue, dependent on tumor size, is most obvious in female dogs, whi-le enlargement of inguinal lymph nodes is often seen in male dogs with penile tumors [12]. The tumor size can vary from 3 to $12 \mathrm{~cm}$ in diameter [32]. Clinical signs of genital are bloody vaginal or preputial discharge, intermittent or persistent ulcerative skin lesions, genital swelling and excessive licking of the genital area [33]. Unpleasant odor or appearance of visible neoplastic masses may also be present [34].

CTVT commonly affects the external genitalia in dogs of both sexes. In males, the tumor is commonly located in the caudal part of the penis, the glans, and occasionally in the foreskin. In females, this tumor is often found at the junction of the vestibule and the posterior region of the vagina and occasionally in the urethral opening (Figure 1) [35]. Dogs with this disease experience pain, hemorrhages and exhibit serosanguineous discharge in 
the external genitalia. Usually cauliflower-like in appearance, friable, and red to flesh colored. The general health of affected dogs is not impaired unless the tumor becomes necrotic and infected or occludes the urethral orifice, or metastasized [36].
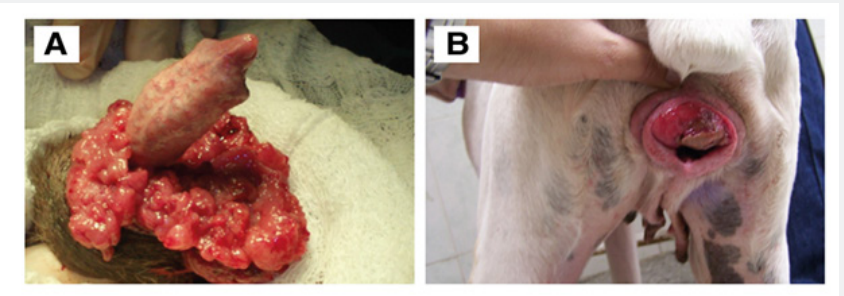

Figure 1: Canine transmissible venereal tumor (CTVT) affecting (A) a male dog (B) a female dog.

It may also develop in extra-genital sites such as skin, subcutaneous tissues and around and in the oral and nasal cavities. Extra-genital tumors are well circumscribed and can measure 2-5 cm [4]. Metastases are rare, yet they can occur, especially in puppies and immunocompromised dogs. These metastases are often considered mechanical extensions of the primary tumor; however, metastases have been reported in inguinal lymph nodes, but can also be seen in the skin, brain, eye, liver, spleen, testicle, and muscle [32].

The ten common signs of cancer in dogs; abnormal swellings that persist or continue to grow sores that do not heal, weight loss, loss of appetite, bleeding or discharge from any of the body openings, offensive odor, difficulty eating or swallowing, hesitation to exercise or loss of stam-ina, persistent lameness or stiffness and difficulty breathing, urinating, or defecating [37].

\section{Diagnostic Approaches}

Tentative diagnosis may be obtained by interview (history) and the presence of an increased volume of light pink color in places like prepuce, vulva and penis, with serous secretion, necrosis, and cauliflower aspect and friable (clinical sign). All these signs suggest the occurrence of TVT, but do not confirm the diagnosis. Definitive diagnosis is based on cytology (such as fine needle aspirates (FNA), imprints of biopsy specimen or in bitches' exfoliate vaginal cytology and/or histopathological examination of surgical or excision biopsy of suspected tumor mass [38].

\section{History of animal}

A medical history of recent travel history to any of these regions, foreign adoption, recent breedi-ng activity and/or recent dog additions to the household should warrant the inclusion of TVT as a differential [39].

\section{Clinical characteristics}

In cases with extra genital localization, clinical diagnosis is usually more difficult because it cause a variety of signs depending on the anatomical localization of the tumor, e.g., sneezing, epitasis, epiphora, halitosis and tooth loss, exophthalmoses, skin bumps, facial or oral deformation along with regional lymph node enlargement. Dogs with genital localization have a hemorrhagic discharge. In males, lesions usually localize caudally on the glans penis, on preputial mucosa or on the bulbus glandis. Tumoral masses often protrude from the prepuce and phimosis can be a complication.

The discharge can be confused with urethritis, cystitis, or prostatitis. In bitches the tumors are of similar gross appearance as in male dogs and can be localized in the vestibule and/ or caudal vagina, protruding from the vulva and frequently causing a deformation of the perineal region. A considerable hemorrhagic vulvar discharge may occur and can cause anemia if it persists. The discharge can attract males and the condition of the bitch can be mistaken for estrus by the owners. Infrequently, it can localize in the uterus. The tumors have highly fragile consistency and cauliflower or papillary appearance [40].

\section{Histopathology Characteristics}

Histopathological examination was performed by removing a fragment of the mass, by cutting with scissors under infiltration of local anesthesia (2\% lidocaine chloridrate without vasoconstrictor). The fragments were fixed in formalin solution and $10 \%$ buffer ( $\mathrm{pH} 7.0$ ) for 24 to 48 hours and then washed in running water for 1 hour. After that, the tumor fragments were processed according to routine technique for optical microscopy and embedded in paraffin. We cut $5 \mu \mathrm{m}$ sections of all the samples, which were stained with haematoxylin and eosin [32].

Histopathologic ally, highly mitotic activity, polychromasia and abundant cytoplasm in pleomor-phic neoplastic cells were observed. The cells were separated into cell islands via thin fibrous tissue and this is a typical feature of tumors [40]. It is composed of round cells, arranged or grouped in strings, interspersed with delicate conjunctival stroma when stained with hematoxylin and eosin. The tumor cells are usually arranged radially around blood and lymphatic vessels and have a high nucleus: cytoplasm ratio with a round nucleus and chromatin ranging from delicate to coarse and prominent nucleoli [34].

The tumor can be classified into progression and initial and final regression phases according to developmental stages. The progression phase presents as round cells arranged diffusely, interspersed by delicate conjunctiva stroma and the frequent presence of mitotic structures. In the initial phase of regression, TILs appear and are widely distributed or associated with the conjunctival stroma. The final regression phase involves collapse of the neoplastic tissue and the frequent presence of apoptotic bodies [41].

\section{Cytopathological Characteristics}

Cytology must be the method of choice for diagnosis of suspected TVT, since the technique is simple, cheap, minimally invasive, and painless and, furthermore, produces much less distortion of cell morphology than biopsy samples fixed in 
formalin. This exam has been used widely in diagnosis. Even in masses localized extragenitally (principally when there is necessity of imaging for diagnosis), and that do not include TVT as a differential diagnosis, the cytological exam was shown to be efficient and conclusive in diagnosing this neoplasia [42].

The cytopathogical samples were collected using a gynecology brush (external genitalia) and fine needle aspiration (FNA) depending on the site of the mass. Two slides were prepared from each tumor, fixed and stained, one by Giemsa staining and the other by the method of Short. Counting was performed using a common optical microscope at a magnification of $10 \mathrm{X}$ to observe the entire extension of the slide and evaluate the quality and quantity of the material. At 400X magn-ification, the cells were observed individually for counting and verification of the characteristics of malignancy. A careful and detailed cytomorphological analysis was done using a reticulated eye piece $(100 / 25$ grid integration with 25 $\mathrm{mm} 2$ area) which delimited the field of cell count, for cellular morphology [42].

When subjected to Romanovisky staining, both genital and extra-genital neoplasias present characteristic round cells with distinct cytoplasmic borders. The nuclei are oval or round and centrally-located, with delicate chromatin and large nucleoli: the cytoplasm is slightly acidophilic and contains finely granular, delicate vacuoles, and cells do not display anisokaryosis, anisocyto-sis, hyperchromasia or nuclear macrokaryosis [43]. Mitoses are frequent, may be typical or atypical, and are indicative of proliferation of tumor cells [42]. Apoptotic bodies of are also observed by cytological exam and are present in higher quantities in the regression phase. Inflammatory cells such as lymphocytes, plasma cells, macrophages and neutrophils are observed regardless of the stage of neoplastic development [28].

Upon cytopathological exam, it is possible to classify this tumor based on the predominant cell type as lymphoid, plasmacytoid or mixed. The lymphoid type of tumor predominantly includes cells with a rounded morphology, scant and finely granular cytoplasm, the presence of vacuoles, and round nuclei with coarse chromatin and the presence of one or two evident nucleoli. In plasmacytoid tumors, most cells have an ovoid morphology, a smaller relative nucleus: cytoplasm ratio and eccentrically located nuclei, the mixed type of tumor exhibits mixed cellularity [44]. The plasmocytic type was being classified as being more malignant [42].

\section{Therapeutic Choices}

Spontaneously and experimentally transplanted to an immunocompetent host shows an initial progressive growth followed by a brief static period and then regression [22]. Because of spontaneous regression is not observed in all cases treatment is recommended. As a form of treatment chemotherapy, surgery, radiotherapy and immunotherapy may be used. The management has not been very easy in dogs, especially in developing countries, as most owners cannot afford the cost of surgical intervention and/ or radiotherapy. Combined use of antitumor drugs has been described as a more effective method of treatment [24].

\section{Surgical Excision}

The complete surgical removal of localized tumors without metastatic involvement is the therapeutic procedure with the highest probability of cure. Surgical excision may be curative in dogs with stage I of the disease and small tumors, easily accessible, well differentiated carcinomas, and noninvasive. Contamination of the surgical site with TVT cells is also a source of recurrence [45]. Complete surgical excision, and chemotherapy with vincristine sulfate $(0.5 \mathrm{mg} / \mathrm{m} 2)$ IV once weekly for $3-6$ weeks is effective [46]. Complete surgic-al excision often cannot be achieved because of the anatomic location of many of these tumors. Recurrence is likely in such cases unless adjunct radiation or chemotherapy is used [47].

\section{Radiotherapy}

TVT are radiosensitive and orthovoltage as well as cobalt have been used for this purpose. Dosa-ge recommendations range from 1500-2500 rads, divided in sessions of 400-500 rads over a period of 1-2 weeks, or a single dose of 1000 rads which, if not curative, can safely be repeated 1-4 times. Radiotherapy lacks practicality due to requirements like trained personnel, specialized equipment and expenses. Therefore, its use is recommended in cases where other treatments fail [36].

\section{Chemotherapy}

Chemotherapy has been shown to be the most effective and practical therapy. Antimitotic agents, such as cyclophosphamide, methotrexate, vincristine, vinblastine or doxorubicin, are the chemo-therapeutic drugs for treating, vincristine sulfate being the most frequently used drug [48]. Single agent therapy with vincristine is the most effective, safe, and appropriate chemotherapeutic agent, resulting in cure even in patients with extra genital metastasis [12]. A cure rate approaching $100 \%$ is achieved in cases treated in the initial stages of progression, especially in cases of less than 1-year duration, and independent of the presence or not of metastases. In cases of longer duration, longer periods of therapy are required, and the cure rate is lower [45].

Major advantages of chemotherapy are the high cure rate, ease of administration and potential usefulness in metastatic, multi-focal disease. The disadvantages of treatment described as side effect. Bone marrow suppression is a possibility under vincristine treatment, and weekly blood tests (such as white blood cell count, hemoglobin and haematocrit) are recommended. Nausea, weight loss, anorexia and vomiting are potential, but uncommon, side effects. Death, although a rare occurrence, has been reported [48]. Spermatogenesis can be temporarily or permanently altered by the administration of 


\section{Cancer Therapy \& Oncology International Journal}

cytotoxic drugs. Drug-altered spermatogenesis may not return to normal for one or more spermatic cycles. Little information is available on the long-term effects of vincristine on male dog fertility. Semen quality in treated dogs does exhibit a transient, short lived deterioration during vincristine treatment [49]. However, semen quality as assessed by volume and sperm count of ejaculate; motility, viability and morphology of sperm deteriorates during the treatment and there is additive effect of duration of vincristine treatment on testicular functions. The semen quality may or may not be regained after vincristine treatment of male dogs and point out that the gonadal response to treatment varies among individuals [36].

The extensive use of vincristine in recent years resulted in the emergence of TVT resistance to the drug [50]. In case of tumors resistant to vincristine, the drug of choice is doxorubicin [48]. The resistance to chemotherapy can be attributed to multifactorial mechanisms, they defects in the regulation of genes that control apoptosis, increased intracellular detoxification mechanisms, changes in DNA repair systems or over-expression and activation molecules such as P-glycoprotein, able to export the chemotherapy out of the cell or cell compartments. The factor chemoresistance is a major challenge in the treatment of patients with cancer. Several factors may contribute to the occurrence of clinical resistance to chemotherapy, and this phenomenon known as multidrug resistance [51].

The resistance to multiple antitumor drugs is a phenomenon characterized by the development of cross-resistance of tumor cells to a wide range of chemically distinct agents after exposure of a single drug may be caused by different mechanisms and constituting a major obstacle for a good chemotherapy successful. The mechanism of multidrug resistance is known as an over-expression of drug efflux pumping membrane bound, the most known P-glycoprotein and multidrug resistance protein drugs, including the group that MRP1 MRP2. The P-glycoprotein is encoded by the MDR1 gene and is associated with resistance to multiple drugs. This P-glycoprotein is character-rized by act as an efflux pump ATP-dependent, actively promoting the exit of the substance within the cell, and when chemotherapy is well within the cell it is able to remove it and prevent action the drug occurs [52]. The P-gp is a substrate for various molecules, including for the antineoplastic drug vincristine [53] and other drugs such as vinblastine, doxorubicin, ivermectins and loperamide [54].

Neurotoxicity is observed in Collies when ivermectin is administered in therapeutic dosages, due to a mutation in the MDR1 gene [54]. The synergistic effect of combination of ivermectin and vincristine that may increase the antitumor effect of the anti-neoplastic agent and reduce resistance to vincristine, which has become increasingly common in recent years [55]. Combination of vincristine and ivermectin was more effective than treatment with vincristine alone, for the treatment [56]. The tumor immunity plays a role in tumor regression after modest chemotherapy [22]. Alternatively, radiation therapy has been shown to be effective against TVT resistant to chemotherapy and at metastatic sites [57].

\section{Prognosis}

The prognosis this disease is very good. Less than $5 \%$ of metastasize to other sites. Vincristine administration is the treatment of choice, with the majority of dogs being cured. Even in the case of metastasis, the cure rate is over $90 \%$. Dogs generally tolerate vincristine administration well; fewer than $15 \%$ of treated dogs experience drug-related side effects. For tumors that are resistant to vincristine, doxorubicin is the most effective chemotherapeutic agent. It have also been shown to be very sensitive to radiation therapy [36].

\section{Control and Prevention}

Control is difficult because stray dogs serve as a reservoir. Measures that are helping to control the transmission are: Managing the number of free-roaming dogs, maintaining strict spay, neuter practices and the effective treatment of clinical cases. Dog owners and breeders should carefully examine all males and females before mating and should also prevent mingling of valued dogs with strays. Careful examination of animals in breeding kennels before mating, with a view to not breeding from affected animals, will control the incidence of the disease. Where these factors have been in operation, the incidence of the disease has fallen, and the disease is rare. Clearly, the best control measure would be one based on breeding only from unaffected individuals, and where random breeding, unsupervised by man, is not permitted [36]. Preventing physical contact between infected dog and others non-infected dog is essential. Wash hands after handling dog and disinfect anything that may be contaminated with living cells from dogs that could come into contact with other dogs. The tumor cannot be transmitted from dogs to other animal species or to people [14].

\section{Conclusion and Recommendation}

In conclusion, TVT in dogs is a naturally occurring tumor transmitted from animal to animal during copulation by viable tumor cells that mainly affects the external genitalia and occasionally the internal genitalia. It responds generally well to treatment and dogs that do undergo spontaneous regression become immune to future tumor challenge. It is the most prevalent neoplasia of the external genitalia of the dog in tropical and sub-tropical urban areas. Due to its regional prevalence among tropic and sub-tropical stray dog populations, it's highly transmissible nature among dogs and its ability to transfer to other wild candidate such as foxes, jackals and coyotes. A large stray dog population and uncontrolled sexual behavior appear to be one reason for high incidence. This type of tumor is seen most commonly in sexually active male and female dogs (2-8 years of age) allowed roaming freely. The management has not been very easy in dogs, especially in developing countries, as most owners cannot afford the cost of surgical intervention and/ or radiotherapy. CTVT in Ethiopia is not clearly known. 


\section{Cancer Therapy \& Oncology International Journal}

Based on the above conclusion the following information should be forwarded:

a. Dogs must be presented by owners and breeders for annual examination and veterinarians must include examination for TVT, including extrusion of penis and digital palpation of the vagina for any growths that may be suggestive of the disease.

b. Stray dogs suspected to have should be impounded for treatment to prevent the spread of the disease and neutering of these dogs may also be beneficial to decrease the sexual activity among dogs in the locality, thus, further preventing the spread of the disease.

c. For those owners with dogs diagnosed with TVT, client education should be highlighted for better compliance (return visit for treatment) and elimination of the tumor from the locality.

d. There must be government policy about strict control of stray dog population to reduce the transmission.

e. Studies should be conducted in Ethiopia in order to determine the status of TVT.

\section{References}

1. Donald M (2002) Tumors in domestic animals, $4^{\text {th }}(E d n)$, Iowa State Press, America, USA pp. 698-699.

2. Prasad A, Vijayanand V, Rajasundaram R, Balachandran C (2007): Cutaneous transmissible venereal tumor in a dog. Indi Vet J 84: 978979

3. Spugnini E, Dotsinsky I, Mudrov N, Citro G, Avino A et al. (2008) Biphasic pulses enhance bleomycin efficacy in a spontaneous canine genital tumor model of chemoresistance: Sticker sarcoma. J Exp Clin Canc Resear 3: 27: 58.

4. Das U and Das A (2000): Review of canine transmissible venereal sarcoma. Vet Resear Comm 24(8): 545-556.

5. Murgia C, Pritchard K, Kim Y, Fassati A, Weiss A (2006) Clonal Origin and Evolution of a Transmissible Cancer. Cell 126(3): 477-487.

6. Ulčar I, Celesk I, Ilievska K, Atanaskova E, Nikolovski G et al. (2012) Cytological diagnostic of canine transmissible venereal tumor case report. Mac Vet Rev 35: 91-96.

7. Eze C, Anyanwu H, Kene R (2007) Review of canine transmissible venereal tumor (TVT) in dogs. Nigerian Vet J 28: 54-70.

8. Demoor-Goldschmidt C, Raynard B (2009) How can we integrate nutritional support in medical oncology? Bulletin du Cancer 96: 665675

9. Mac-Ewen E (2001): Transmissible venereal tumor. In: Withrow S and MacEwen E (eds.), Small Animal Clinical Oncology. $3^{\text {rd }}$ Edition, Saunders, Philadelphia pp. 651-656.

10. Trevizan J, Carreira J, Souza N, Carvalho I, Gomes P et al. (2012) Disseminated transmissible. Vet Resear Comm 24: 545-556.

11. Lorimer L, Fan T (2007) Canine transmissible venereal tumor. In: Withrow S, Vail D(ed.): Small Animal Clinical Oncology. $4^{\text {th }}$ Edition, St. Louis, MO, USA: Elsevier pp. 799- 803.

12. Martins M, De-Souza M, Ferreira F, Gobello C (2005) Canine transmissible venereal tumor: Etiology, pathology, diagnosis and treatment. Recent Advances in Small Animal Reproduction. Retrieved 2006-05-25.

13. Rebbeck C, Thomas R, Breen M, Leroi A, Burt A (2009) Origins and evolution of a transmissible cancer. Evolution 63(9): 2340-2349.

14. Frank U (2007): The evolution of a malignant dog. Evol Dev 9(6): $521-$ 522.

15. Dingli D, Nowak M (2006): Cancer biology: infectious tumor cells. Nature 443: 35-36.

16. Murchison E (2009): Clonally transmissible cancers in dogs and Tasmanian devils. Oncogene 27: 19-30.

17. Bridgett M, vonHoldt T, Elaine A Ostrander D (2006) The Singular History of a canine Transmissible Tumor. Cell 126(3): 445-447.

18. Kabuusu R, Stroup D Fernandez C (2010) Risk factors and characteristics of canine tran-smissible venereal tumours in Grenada. West Indies. Vet and Comp. Oncol 8(1): 50-55.

19. Gonzalez C, Sanchez B, Velez H, Buen D (1997) Neoplasms of the reproductive system in bitches: Retrospective study over 6 years. Vet Mex 28: 31-34.

20.Scarpelli K (2008) Predictive factors for the regression of canine transmissible venereal tumor during vincristine therapy. Vet J 183: 362-363.

21. Liu C, Wang Y, Lin C, Chuang T, Liao K et al. (2008) Transient down regulate on of monocyte-derived dendritic cell differentiation, function, and survival during tumor progression and regression in an in vivo canine model of transmissible venereal tumor. Cancer Immunol Immunother 57(4): 479-491.

22. Gonzalez C, Griffeys S, Naydan D, Flores E, Cepeda R et al. (2000) Canine transmissible venereal tumor: a morphological and immunohistochemical study of 11 tumors in growth phase and during regression after chemotherapy. J Comp Patho 122(4): 241-248.

23. Liao K, Hung S, Hsiao Y, Bennett M, Chu R (2003) Canine transmissible venereal tumor cell depletion of B lymphocytes: molecule(s) specifically toxic for B cells. Vet Immunol Immunopathol 92: 149-162.

24. Liu C, Wang Y, Lin C, Chuang T, Liao K et al. (2008) Transient down regulate on of monocyte-derived dendritic cell differentiation, function, and survival during tumor progression and regression in an in vivo canine model of transmissible venereal tumor. Cancer Immunol Immunother 57(4): 479-491.

25. Hsiao Y, Liao K, Chung, T, Liu C, Hsu C et al. (2008) Interactions of host IL- 6 and IFN-gamma and cancer derived TGF-beta 1 on MHC molecule expression during tumor spontaneous regression. Cancer Immunol Immunother. 57: 1091-1104.

26. Hsiao Y, Liao K, Hung S, Chu R (2002) Effect of tumor infiltrating lymphocytes on the expression of MHC molecules in canine transmissible venereal tumor cells. Vet Immun Immunol 87(1): 19-27.

27. Hsiao Y, Liao K, Hung S, Chu R (2004): Tumor infiltrating lymphocyte secretion of IL- 6 antagonizes tumor-derived TGF-beta 1 and restores the lymphokine-activated killing activity. J Immunol 172(3): 15081514.

28. Santos J, Barbosa M, Tenorio A, Coelho M, Rolim M et al. (2008) Transmissibl-e venereal tumor disease in a dog with involvement of the skin. Arq Bras Med Vet Zootec 2: 39-43.

29. Mukaratirwa S, Chiwome T, Chitanga S, Bhebhe E (2006) Canine transmissible venere-al tumor: assessment of mast cell numbers as indicators of the growth phase. Vet Resear Comm 30: 613-621.

30. Amaral A (2007): Cytomorphological characterization of transmissible canine venereal tumor. R. P. C. V., 102: 253-260. 


\section{Cancer Therapy \& Oncology International Journal}

31. Albanese F (2006): Extra-genital transmissible venereal tumor associated with circulating neop-lastic cells in an immunologically compromised dog. Vet and Comp Oncol 4(1): 57-62.

32. Park M, Kim Y, Kang M, Oh S, Cho D (2006) Disseminated trans-missible venereal tumor in a dog. J Vet Diag Invest 18(1): 130-133.

33. Nak D, Nak Y, Cangul I, Tuna B (2005) A clinic pathological study on the effect of vin-cristine on transmissible venereal tumor in the dogs. J Vet Med A Physiol Pathol Clin Med 52(7): 366-70.

34. Santos F, Vasconcelos A, Nunes J, Cassali G, Paixao T et at.al (2005) The canine transmissible venereal tumor general aspects and molecular approach (Review). Basic J 21: 41-53.

35. Madewell R (2001) Cellular proliferation in tumors: a review of methods, interpretation, and clinical applications. J Vet Intern Med 15(4): 334- 40

36. Gandotra V (2014): Transmissible venereal tumors in dogs. Animal Husbandry Officers Workshop pp. 5.

37. Douglas H. (2003): Textbook of small animal surgery. $2^{\text {nd }}($ Edn), Washington, WB Saunders pp. 2437.

38. Erünal-Maral N (2000): Use of exfoliative cytology for diagnosis of transmissible venereal tumor and controlling the recovery period in the bitch. Dtsch Tierarztl Wochenschr 107(5): 175-180.

39. Merck Veterinary Manual (2008) Canine Transmissible Venereal Tumor: Merck and Co. Inc. Whitehouse Station, N. J. U. S. A. I. N. (1998) Transmissible venereal tumor: a consequence of sex tourism in a dog Can Vet J 39: 591.

40. Schlafer D Miller R (2007): Female genital system. In: Jubb, Kennedy and Palmer's Pathology of Domestic Animals, vol 3, chapter 4, 4 Edition, M. Grant Maxie. China pp. 123-129.

41. Mukaratirwa S, Gruys E (2004) Canine transmissible venereal tumor: cytogenetic origin, immunophenotype, and immunology. A review. Vet Q 25(3): 101-111.

42. Amaral A, Gaspar L, Silva S and Rocha N (2004): Cytological diagnostic of transmissible venereal tumor in the Botucatu region, Brazil (descriptive study: 19942003). R. P. C. V. 99: 167171

43. Denicola D, Cowell R, Tyler R, Meinkoth J, Denicola D (2007) Diagnostic cytology and hematology of the dog and cat, $3^{\text {rd }}$ Edition, St. Louis, Mosby pp. 68-69.

44. Greatti W, Amaral A, Silva S, Gaspar L, Barbisan L et at.al (2004) Proliferation indexes determination by CEC and Ki-67 in fine needle aspiration cytology of transmissi-ble venereal tumor. Arch Vet Sci 9 53-9.

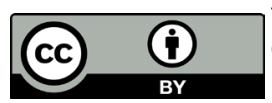

This work is licensed under Creative

Commons Attribution 4.0 License

DOI: 10.19080/CTOIJ.2019.14.555895
45. Boscos C, Ververidis H (2004): Canine TVT Clinical findings, diagnosis and treatment. Sci. Proc Wsava Fecava Hvms World Congress, Rhodes, Greece 2: 758-761.

46. Johnson C (2005): Transmissible Venereal Tumor. In: Merck Veterinary Manual, $9^{\text {th }}$ Edition, Edited by Cynthia M. Kahn. Merck and Co. Inc. Whitehouse Station, N. J, U. S. A. Pp. 1165

47. Merck Veterinary Manual (2008): Canine Transmissible Venereal Tumor: Merck and Co. Inc. Whitehouse Station, N. J. U. S. A. I. N. (1998) Transmissible venereal tumor: a conseq-uence of sex tourism in a dog Can Vet J 39: 591

48. Nak D, Nak Y, Cangul I, Tuna B (2005) A clinic pathological study on the effect of vin-cristine on transmissible venereal tumor in the dogs. J Vet Med A Physiol Pathol Clin Med. 52(7): 366-70.

49. Gobello C Corrada Y (2002): Effects of vincristine treatment on semen quality in a dog with a TVT. J Small Anim Prac 43: 416-417.

50. GasparD, Amaral A, Bassani-Silva S, Rocha N (2009) Imunorreatividade à p-gp no tumor venéreo transmissível canino. Vet. em. Foco 6: 140146

51. Maia R, Rumjanek V, Ferreira C, Rock (2004) Molecular mechanisms of multidrug resistance in: Molecular Oncology. São Paulo: Atheneu pp. 113-122.

52.Zandem J (2005): Reversal of in vitro cellular MRP1 and MRP2 mediated vincristine resistance by the flavonoid myricetin. Biochem Pharma Califó 69: 1657 -1665.

53. KorystovY, Ermakova N, Kublik L, Levitman M, ShaposhnikovaVet at.a (2004) Avermectins inhibit multidrug resist-ance of tumor cells. Eur J Pharmacol 493: 57-64.

54. Mealey K, Northrup N, Bentjen M (2003) Increased toxicity of P-glycoprotein substrate chemotherapeutic agents in a dog with the MDR1 deletion mutation associated with ivermectin sensitivity. J Am Vet Medi Asso 223(10): 1453-1455.

55. Dowling P (2006): Pharmacogenetics: it's not just about ivermectin in collies. Cana Vet J 47(12): 1165-1168.

56. Andrade S, Sanches O, Gervazoni E, Lapa F and Kaneko V (2009) Comparação entre dois protocolos de tratamento do tumor venéreo transmissível em cães. Clín. Vet 14: 56-62.

57. Rogers K, Walker M, Dillon H (1998) Transmissible venereal tumor: Retrospective study of 29 cases. J Ame Anim Hosp Asso 34(6): 463470.

\section{Your next submission with Juniper Publishers will reach you the below assets}

- Quality Editorial service

- Swift Peer Review

- Reprints availability

- E-prints Service

- Manuscript Podcast for convenient understanding

- Global attainment for your research

- Manuscript accessibility in different formats

( Pdf, E-pub, Full Text, Audio)

- Unceasing customer service

Track the below URL for one-step submission https://juniperpublishers.com/online-submission.php 